\title{
Mitogenic Effect of a Novel Animal Lectin on Human Lymphocytes
}

\author{
Hiroshi Matsuo* and Katsumi Murata \\ Department of Medicine and Physical Therapy, University of \\ Tokyo School of Medicine, Tokyo 113
}

\begin{abstract}
Matsuo, H. and Murata, K. Mitogenic Effect of a Novel Animal Lectin on Human Lymphocytes. Tohoku J. exp. Med., 1979, 129 (4), 347-349 — The mitogenic effect of the novel lectin prepared from an animal source on human lymphocytes was examined in comparison with that of phytohemagglutinin-p (PHA-p) by the uptake of ${ }^{3} \mathrm{H}$-thymidine. The uptake of ${ }^{3} \mathrm{H}$-thymidine by lymphoblasts was enhanced by the treatment with the lectin as well as with PHA-p, though the effect of the lectin was difficult to compare exactly with that of PHA-p. — animal lectin; human lymphocyte; mitogen effect
\end{abstract}

Numerous studies have been described on mitogen effects of various plant lectins. However, information on the effect of the lectin prepared from animal sources is still limited. The present paper describes a lymphoblast stimulating effect by an animal lectin from the hemolymph of a horseshoe crab Tachypleus tridentatus and a comparison of the specificity of the lectin with that of phytohemagglutinin-p (PHA-p).

\section{Materials and Methods}

Ten $\mathrm{ml}$ of blood were withdrawn by vein puncture from healthy individuals and the lymphocytes were prepared on Ficoll-Conray gradient by the method reported previously (Boyum 1968; Salem and Morse 1976). Ficoll was obtained from Pharmacia Fine Chemicals and $60 \%$ Conray was purchased from Mallinkrodt Pharmaceuticals, St. Louis. The separated lymphocytes were washed with TC 199 medium (Gibco, Grand Island) containing 100 units/ml penicillin and then suspended in TC 199 culture medium with $20 \%$ normal human serum (Flow Laboratories) at the rate of $6 \times 10^{5}$ cell per $\mathrm{ml}$ of the medium. $0.1 \mathrm{ml}$ each of the cell suspended was poured in a plastic microtiter plate (Towa Kagaku, Tokyo): each culture well has $0.60 \mathrm{~cm}^{3}$ capacity (diameter, $6 \mathrm{~mm} \times$ height, 17 $\mathrm{mm})$. The appropriate dose of the mitogen was as follows: A novel animal mitogen was prepared from the hemolymph of the Japanese horseshoe crab Tachypleus tridentatus and purified by the methods reported previously (Roche and Monsigny 1974; Shimizu et al. 1977). Either $5 \mu$ l of the lectin or $100 \mu \mathrm{g}$ of PHA-p (Difco Laboratories, Detroit, Michigan) were added to the prepared well. The cultures were placed in a $5 \% \mathrm{CO}_{2}$ and $95 \%$ air incubator at $37^{\circ} \mathrm{C}$ for $72 \mathrm{hr}$.

At $48 \mathrm{hr}$ after the start of the experiment, they were pulsed with $5 \mu \mathrm{Ci} /$ well of

Received for publication, November 14, 1978.

* Present address: Department of Rheumatology, University of London, Royal Postgraduate Medical School, Hammersmith Hosptial, Du Cane Road, London WI2 OHS, England. 
${ }^{3} \mathrm{H}$-thymidine (specific activity $49.8 \mathrm{Ci} /$ mmole, New England Nuclear Corp., Boston) and incubated for $24 \mathrm{hr}$. The cells in the microtiter culture were washed twice with $0.5 \mathrm{ml}$ of $0.83 \%$ ammonium chloride and treated with $5 \%$ trichloroacetic acid. The cells were then aspirated onto Whatman glass fiber filter with a harvester and washed by aspiration of acetone (Harrison et al, 1974). After being dried at $37^{\circ} \mathrm{C}$ for $15 \mathrm{~min}$, the individual filters were placed in scintillation vials with $5 \mathrm{ml}$ of a standard scintillation fluid (l.5 mg POPOP, $20 \mathrm{mg}$ DPO in $5 \mathrm{ml}$ toluene), and counted by a Beckman liquid scintillation spectrometer. The counting procedure was performed in triplicate culture and the result was expressed as the mean of the triplicate.

As the preliminary experiment, the dose response and incubation time of the animal lectin and PHA-p were determined on normal individuals with autologous serum. PHA-p was used at the concentration of $100 \mu \mathrm{g} / 0.1 \mathrm{ml}$ medium. The animal lectin was used at the concentration prepared from hemolymph of the horseshoe crab.

Trypan blue viability indicated $90-95 \%$ dye exclusion with both mitogens. The cells of the untreated control grew morphologically in normal states under the condition used here, whereas either the lectin or PHA-p stimulated cells to form lymphoblasts.

\section{Results and Discussion}

Significantly enhanced response to the novel animal mitogen prepared from the hemolymph of the Japanese horseshoe crab Tachypleus tridentatus, as well as PHA-p was obtained by lymphocytes of healthy individuals. Morphological examination for cell growth was performed using lymphocytes in a well. The animal lectin as well as PHA-p stimulated lymphocytes to form blastoid formation. By microscopic survey, lymphoblastic changes were found much more frequently by treatment with PHA-p than with the lectin under the condition used here. The lectin stimulated the lymphocytes: $45-65 \%$ of the cells responded to form lymphoblasts, whereas $85-90 \%$ cells responded to the PHA-p.

Table 1 shows the comparative effect of the stimulation of the novel animal lectin and PHA-p on the lymphocytes in healthy individuals. When the lectin

TABLE 1. Lymphocyte stimulation effect by animal lectin and phytohemagglutinin-p

\begin{tabular}{ccc}
\hline Name & Animal lectin & Phytohemagglutinin-p \\
\hline I.E. & $5,075^{*}$ & 16,089 \\
S.H. & 4,937 & 25,186 \\
M.T. & 6,897 & 38,977 \\
S.N. & 5,820 & 21,450 \\
S.M. & 7,104 & 14,316 \\
K.Y. & 2,449 & 14,479 \\
U.K. & 4,566 & 25,600 \\
N.X. & 4,859 & 14,244 \\
Y.T. & 3,076 & 13,978 \\
Average & 4,976 & 20,480 \\
Standard & 1,457 & 7,930 \\
deviation & & \\
\hline
\end{tabular}

* The numbers are expressed as counts per minute of ${ }^{3} \mathrm{H}$-thymidine incorporation per culture. The mean count of no mitogen was $355 \mathrm{cpm}$ and ranged from $285 \mathrm{cpm}$ to 425 cpm per culture. 
was added to the prepared lymphocytes, the uptake of methyl- ${ }^{3} \mathrm{H}$-thymidine was enhanced more than 10 -fold of the untreated control prepared from the same individuals. In the same condition, PHA-p stimulated lymphocytes and the incorporation rate of the ${ }^{3} \mathrm{H}$-thymidine was accelerated significantly. The triplicate experiment resulted in $15 \%$ difference within the same run, but the enhanced uptake of the ${ }^{3} \mathrm{H}$-thymidine was statistically significant in comparison with that of the untreated control. The stimulation response to the lymphoblasts by the two mitrogens was not exactly the same. It may be due to somewhat different mechanism by which the blastoid formation occurred. The lectin had been reported to give different agglutination titers for erythrocytes from several sources (Shimizu et al. 1977). The difference may also occur by different states of lymphocytes, either at normal or pathological conditions. An elucidation, therefore, of difference of the stimulation effect by the novel lectin on lymphocyte transformation might prove useful for the study of pathogenesis of certain autoimmune disease.

\section{Acknowledgments}

The study was supported in part by Scientific Grants from the Ministry of Education, Science and Culture, Japan. We are grateful to Dr. T. Nakahara, Seikagaku Kogyo Co., Tokyo, for providing the animal lectin.

\section{References}

1) Boyum, A. (1968) Isolation of mononuclear cells and granulocytes from human blood. Scand. J. Clin. Lab. Invest., 12, Suppl. 97, 77-89.

2) Harrison, M.R., Thurman, G.B. \& Thomas, G.M. (1974) A simple and versatile harvesting device for processing radioactive label from cells in microculture. $J$. immunol. Methods, 4, 11-16.

3) Roche, A.-C. \& Monisgny, M. (1974) Purification and properties of limulin: a lectin (agglutinin) from hemolymph of Limulus polyphemus. Biochim. biophys. Acta, 371, 242-254.

4) Salem, N.B. \& Morse, J.H. (1976) Lymphocyte response to mitogens in progressive systemic sclerosis. Arthritis and Rheumatism, 19, 875-882.

5) Shimizu, S., Ito, M. \& Niwa, M. (1977) Lectins in the hemolymph of Japanese horseshoe crab, Tachypleus tridentatus. Biochim. biophys. Acta, 500, 71-79. 